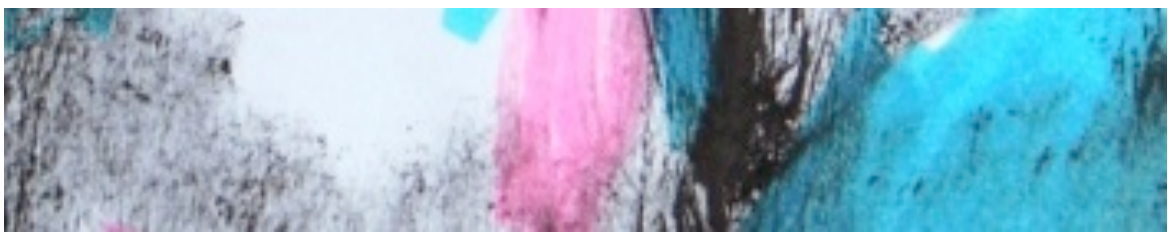

\title{
Identidad y responsabilidades socioeducativas del mediador escolar y del mediador intercultural: hacia una clarificación de funciones
}

\section{Identity and socio-educational responsibilities of the educational mediator and the intercultural mediator: towards a clarification of functions}

\author{
María Jesús Martínez Usarralde ${ }^{(*)}$ \\ Universitat de València - España \\ m.jesus.martinez@uv.es \\ Piedad Sahuquillo Mateo ${ }^{(* *)}$ \\ Universitat de València - España \\ piedad.sahuquillo@uv.es \\ Laura García Raga ${ }^{(* * *)}$ \\ Universitat de València - España \\ laura.garcia@uv.es
}

Resumen

El presente artículo reconoce que, ante la creciente presencia en escenarios socioeducativos de
Abstract

It is a well-known fact that the demand for professional mediators will increase in their

Mediaciones Sociales, № 11, II semestre 2012, pp. 47-71. ISSN electrónico: 1989-0494. http://dx.doi.org/10.5209/rev_MESO.2012.v11.41269 
«Identidad y responsabilidades socioeducativas del mediador escolar y del mediador...»

la figura profesional del mediador en los dos ámbitos principales relacionados con la educación (el escolar y el intercultural), deben identificarse los rasgos idiosincrásicos de cada uno de ellos, lo que no es óbice para reconocer cómo, a pesar de que existen, en efecto, diferencias en la definición de estos dos modelos de mediación, se evidencian aspectos coincidentes que los vinculan a un tronco común: las competencias y responsabilidades socioeducativas que adquieren cada uno de ellos. Las autoras del artículo aplican la metodología comparada para demostrar ambas realidades compatibles en las figuras del mediador escolar y el mediador intercultural, respectivamente.

Palabras clave: mediación escolar, mediación intercultural, competencia educativa, mediador escolar, mediador cultural, metodología comparada. two characteristic fields of work, that is in schools and in intercultural education. The aims of this article will be to identify their distinctive responsibilities. While there can be no doubt that differences exist, their identification could well prove to be an impediment to the understanding of their performance as there also are, indeed, important identical aspects of their socio-educational responsibilities.

The authors of this article employ the comparative method in order to demonstrate that both workplace studies (school mediator and cultural mediator) are compatible with one another.

Keywords: educational mediation, intercultural mediation, educational competence, educational mediator, cultural mediator, comparative methodology. 


\section{Presentación}

Pocas profesiones en el ámbito de lo socioeducativo se han demandado con tanta imperiosidad en los últimos años como la que se vincula, en sensu lato, con la mediación, en sus múltiples facetas. La respuesta a por qué, en estos momentos, la profesión de mediador ${ }^{1}$ emerge con increíble fuerza en los escenarios formativos tanto formales (en el universitario, ya sea a través de asignaturas concretas, ya de diplomas, postgrados y máster, entre otros) como no formales (cursos y talleres ofrecidos desde asociaciones, empresas, organizaciones no gubernamentales, etc.) obedece a diferentes y variadas peticiones, de entre las que destacaremos fundamentalmente dos.

En primer lugar, son los propios contextos actuales, cada vez más imbricados en cuanto a número de protagonistas involucrados en los mismos, los que precisan desde un punto de vista técnico e incluso humano, la presencia de profesionales que puedan interpretar y, sobre todo, gestionar los diferentes conflictos (concepto este que se carga de nuevos significados) que van sucediendo de manera procesual, a fin de desentrañarlos. Y, en segundo lugar, derivada de manera natural del primer motivo, los propios grupos de trabajo interdisciplinares, inmersos en una sociedad cada vez más plural, heterogénea y diversa, están solicitando figuras profesionales ante las que los especialistas más clásicos (pedagogos, educadores sociales, maestros, profesores, psicopedagogos, etc., si se habla del ámbito estrictamente educativo) "no llegan”. Así, a partir de los déficits detectados, por ejemplo, en elaborar y dirigir tanto protocolos especializados y modelos de convivencia en los centros escolares y en otras instituciones como los SEAFIS (Servicio Especializado de Atención a la Familia y a la Infancia), como gestionar metodologías para solventar los conflictos escolares, interculturales, familiares, comunitarios, etc., se forja de manera casi obligada la figura del mediador.

A partir de esta premisa, el estado de la cuestión actual que trabaja tanto sobre análisis globales de los ámbitos de mediación (Díez y Tapia, 1999; Aguado et al., 2002; Vinyamata, 2003; Romero, 2006 y Hoyos, 2007) como sobre cada uno de ellos, de manera especializada, es, en estos momentos, muy prolífico, obedeciendo en buena manera a esta demanda de exploración heurística de necesidades y retos variados a los que se ha hecho referencia.

1 A partir de ahora, utilizaremos el término "mediador" para referirnos a este profesional tanto del género masculino como femenino.

Mediaciones Sociales, № 11, II semestre 2012, pp. 47-71. ISSN electrónico: 1989-0494. http://dx.doi.org/10.5209/rev_MESO.2012.v11.41269 
Así, aun a riesgo de olvidar autores significativos en cada uno de ellos, en España destacan, por sus estudios y aportaciones a la consolidación definitiva de la denominada "cultura de mediación", dentro de la mediación escolar: Boqué (2003), Viñas (2004), Munne y Mac-Cragh (2006) y García y López (2007). En mediación familiar, hay que nombrar los estudios de Bernal y Andrés (1991), Méndez (1997), Ortuño (2000), Osma y Loza (2000), RipollMillet (2001), Romero (2002), García (2003), Suares (2003), Parkinson (2005) y García Villaluenga (2006). Finalmente, en mediación intercultural $\mathrm{y}$, partiendo incluso de que no hay ni siquiera unicidad en la propia denominación: Martínez (2008), los análisis realizados por Cohen-Emerique (1997), Giménez (2001), AEP-Desenvolupament Comunitari (2002) y Malik y Herraz (2005), han establecido líneas directrices teóricas que ayudan a configurar este campo, menos desarrollado que los anteriores.

Ahora bien, y como muy bien explicita Giménez (2008), ante un panorama tan extremadamente heterogéneo y especializado de este nicho laboral, se corre precisamente el "riesgo de la no mediación", es decir, que a través de la especialización extrema se pierda el tronco común de la mediación. Esta realidad es evidenciada en diferentes estudios en los que se pone de manifiesto la escasa conexión existente entre los dos tipos de mediadores a los que vamos a referirnos en este estudio: el mediador escolar y el mediador intercultural, ya sea en congresos, en acuerdos sobre terminologías, metodologías utilizadas, etc. Desde esta aportación se pretende superar, precisamente, este escollo de base, utilizando el método comparado y defendiendo la hipótesis de que, a pesar de que existen diferencias en la definición de estos dos modelos de mediación, se reconocen aspectos coincidentes que los vinculan a un tronco común: las competencias educativas que adquieren cada uno de ellos. Cabe señalar aquí que, a nuestro entender y recogiendo los planteamientos de Escudero (2009), el concepto competencia exige de una perspectiva multidimensional e integral en aras a contemplar todos los componentes que las configuran (cognitivos, personales, sociales y éticos) y a favorecer la capacidad de aprender a aprender. Así pues, se evidenciarán los matices que, dentro del escenario educativo, diferencian a cada uno de los dos, con lo que no se defenderá la integración de los dos modelos de mediación en las instituciones educativas, pero sí el establecimiento de redes y equipos interdisciplinares de los tres profesionales de la mediación aquí citados, gestores por excelencia de los diferentes conflictos que surgen en la vida diaria por parte de los diferentes actores sociales y que cumplen, por ello, papeles complementarios en el escenario socioeducativo. 


\section{Planteamiento de la investigación: PRopuesta metodo- LÓGICA COMPARADA Y ANÁLISIS DE LOS ÁMBITOS (FASE ANALÍTICA)}

\subsection{Propuesta metodológica: método comparado}

El método comparado utilizado se basa en una adaptación personal a la metodología de García Garrido (1990) y Ferrer (2002) que contempla estas tres fases: estudio descriptivo ("fase analítica"), en el que se describirán los tres modelos y se acomete un análisis formal y material, además de explicativo, al tiempo que se delimitan y clasifican las categorías de análisis (tertium comparationis); estudio comparativo ("fase sintética"), en el que los datos son seleccionados y yuxtapuestos en tablas, a fin de facilitar su comparación, y, finalmente, la "fase de conclusiones comparadas", en la que se reflexionará sobre los resultados hallados, al tiempo que se sugerirán vías por las que seguir analizando e investigando sobre diferentes aspectos de esta figura, a la luz de la hipótesis presentada.

Antes de comenzar con la primera de las fases, las autoras desean destacar que, para su comparación, se ha recurrido a "modelos tipo" de cada una de las unidades de comparación, confeccionando para ello tipos ideales desde el plano teórico basados en la bibliografía e investigaciones consultadas dentro de cada uno de los dos ámbitos seleccionados: la mediación escolar y la mediación intercultural.

\subsection{Análisis de los modelos (fase analítica)}

En este primer momento del método, como ya se ha señalado, se ofrece un análisis descriptivo de los tres modelos escogidos, que se transforman en unidades de comparación en este estudio. Una vez presentadas, se seleccionan los criterios de comparación (tertium comparationis) escogidos, a fin de ayudar a la comprensión de la próxima fase.

\subsubsection{Mediación escolar}

Es una realidad comprobada que "la convivencia se ha convertido en un tema de máxima prioridad para las sociedades del siglo XXI y que los centros educativos pueden y deben cumplir un papel primordial en su aprendizaje” (López y García, 2006: 85-97). Esta circunstancia exige de nuevas estrategias dirigidas a responder con mayor eficacia a la realidad

Mediaciones Sociales, № 11, II semestre 2012, pp. 47-71. ISSN electrónico: 1989-0494. http://dx.doi.org/10.5209/rev_MESO.2012.v11.41269 
educativa actual y a las demandas sociales presentes. La mediación es, entre algunas otras, la herramienta más utilizada en los últimos tiempos como un instrumento no solo para resolver posibles conflictos, sino para crear una cultura pedagógica capaz de revitalizar la mejora de la convivencia en los centros educativos.

Si recurrimos a la historia, podemos decir que la mediación se traslada al ámbito educativo en Estados Unidos durante los años sesenta de la mano de dos movimientos diferenciados: el de la cultura de paz y justicia y el del aprendizaje cooperativo en el aula (Slyck y Stern, 1996; Jares, 2001 y Pérez, 2002). No obstante, diversos autores destacan a los llamados "cuáqueros", una religión de origen cristiano surgida durante el tiempo de la Reforma en Inglaterra, como los pioneros en la implantación de la mediación en la sociedad americana a través del programa Children's Creative Response to Conflict (CCRC), surgido en Nueva York en 1972 con la idea de construir una comunidad donde los niños sean capaces de tener una buena comunicación, compartan sentimientos y se acostumbren a resolver los problemas de forma creativa (Six, 1997; Rozemblum, 1998 y Vinyamata, 2003). Con posterioridad, la mediación fue expandiéndose de manera rápida, fruto, sin duda, de los buenos resultados que proporcionaba y vio reconocida su importancia como campo de estudio e intervención, sobre todo con la fundación en 1984 de la National Association for Mediation in Education (NAME).

En España tendremos que esperar a 1993 para que se desarrolle uno de los programas pioneros de mediación escolar; surge en el País Vasco, desde el Centro de Investigación para la Paz Gernika Gogoratuz (Gernika Gogoratuz, 1994 y Uranga, 1997), dedicándose durante varios años a llevar a cabo actividades en forma de charlas y seminarios con profesores de diversas etapas escolares relacionadas con la educación para la paz desde la perspectiva de la transformación de conflictos.

Si entramos ahora en aspectos relacionados con la inclusión de la figura del mediador en el terreno legislativo, por un lado, y a nivel estatal, debemos destacar la Ley 27/2005, de 30 de noviembre, de fomento de la educación y la cultura de la paz, la cual establece una serie de medidas destinadas al ámbito educativo y de investigación, con el objeto de establecer la cultura de paz y no-violencia en nuestra sociedad. En el artículo $2^{\circ}$ se indican las tareas que el Gobierno llevará a cabo para lograr el fomento de la paz, de las cuales resaltamos la séptima: “promover la formación especializada de hom- 
bres y mujeres en técnicas de resolución de conflictos, negociación y mediación”. Asimismo, la Ley Orgánica de Educación (LOE, 2006) introduce entre sus objetivos novedosos el referente a la prevención y resolución de conflictos y, por tanto, de una manera indirecta se alude a la mediación.

Por otro, centrando nuestra atención en el ámbito autonómico, es obligado señalar algunos documentos normativos reguladores de los derechos y deberes de los alumnos y normas de convivencia, en donde se señalan algunos aspectos vinculados a la misma: Decreto 292/1995, de 3 de octubre, de la Comunidad Autónoma de Canarias, modificado por el Decreto 81/2001, de 19 de marzo; Decreto 279/2006, de 4 de julio, de Catalunya (DOGC 06-VII-2006); Decreto 50/2007, de 20 de marzo, de la Comunidad Autónoma de Extremadura (DOE 27-III-2007); Decreto 51/2007, de 17 de mayo, de Castilla y León (BOCyL 23-V-2007) (capítulo IV del título III); así como el Decreto 39/2008, de 4 de abril, de la Comunidad Valenciana (DOGV 09-IV-2008).

$\mathrm{Si}$ atendemos ahora a las influencias recibidas por tres escuelas relevantes, podemos distinguir tres modelos de mediación (Suares, 1996):

1. Modelo directivo: está centrado en llegar a un acuerdo y se encuentra influido por la Escuela de Negociación de Harvard. La mediación es entendida como un método de resolución de conflictos conducido por un mediador neutral e imparcial que dirige a las partes en la negociación de un acuerdo. El éxito de la mediación se alcanzará cuando se llegue a un acuerdo que resuelva el problema y satisfaga las necesidades de todas las partes.

2. Modelo transformativo: el elemento primordial del proceso de mediación es la metamorfosis que cada persona inmersa en un conflicto lleva consigo, a través del descubrimiento de sus propias habilidades y del desarrollo de una mayor apertura hacia las otras partes disputantes. El mediador no se centra en la solución del problema, ya que son las personas implicadas en el conflicto las que deben adoptar decisiones sin que se ejerza sobre ellos influencia. La interacción entre ellas es clave.

3. Modelo circular-narrativo: focalizado en las narraciones o discursos de las personas que tienen un conflicto y que participan en el proceso de mediación. El trabajo del mediador de esta orientación, va dirigido a descubrir aquellos hechos que contradigan algún aspecto de las historias narra- 
das por los participantes para lograr el cambio en el punto de partida que han tomado y, así, conseguir una comunicación cooperativa.

En relación a quién es el que asume la figura de mediador, los expertos aluden que cualquier miembro de la comunidad educativa: profesores, alumnos, padres y personal no docente, entre los más usuales. Lo que sí es aconsejable, por otra parte, es que los mediadores trabajen en equipo y actúen en los conflictos en parejas (co-mediación), ya que facilita captar diferentes percepciones del conflicto, permite un mayor control del proceso de mediación y dota de tranquilidad a los propios mediadores.

Por otra parte, en algunas Comunidades Autónomas sí se ha contemplado recientemente la posibilidad de la contratación de profesionales externos como agentes mediadores y responsables de las cuestiones sociales de los procesos educativos. Una de las Comunidades pioneras ha sido Extremadura, en donde se ha implantado la figura del educador social en los centros educativos de secundaria, integrado en el Departamento de Orientación y ejerciendo la resolución de conflictos y mediación entre otras muchas funciones (control del absentismo escolar, relaciones con la familia, apoyo al profesorado, etc.). En el caso señalado, el proceso de contratación del educador social se inicia en septiembre del 2002, exigiéndole la Diplomatura de Educación Social y asociándolo, por lo que respecta a su relación contractual con la Junta de Extremadura, al personal de administración y servicios. Así pues, "sus condiciones laborares se asemejarán a administrativos, conserjes y personal de los centros de enseñanza” (Galán, 2008: 57-71).

De todas formas, es más frecuente que los mediadores sean miembros de la comunidad educativa y, sobre todo, alumnos, al implicar una mayor proximidad y simetría que si los mediadores fueran una figura de autoridad como los profesores. Los programas de mediación entre iguales entienden la mediación como un recurso que permite a los estudiantes un mayor control de sus capacidades y de su vida, en la idea de que es mejor que sean ellos quienes manejen sus propios problemas, aunque ello signifique que los docentes y directivos no ejerzan tanto control sobre determinados conflictos.

De manera general, los mediadores reciben la formación en su centro educativo a través de cursos y talleres, bien sea por medio de un grupo de 
docentes que han recibido formación previa en temas vinculados con la temática en el Centro de Formación del Profesorado al que pertenezca el centro o por medio de algún asesor externo que forma al equipo de mediación en el propio centro educativo.

Una vez finalizada la formación, se constituye el equipo de mediación del centro, que debe reunirse periódicamente para valorar los casos que pueden ser mediados, elaborar documentos que faciliten el proceso, evaluar su funcionamiento, proponer las mejoras necesarias $\mathrm{y}$, prioritariamente, actuar en los conflictos surgidos entre miembros de la comunidad educativa para ayudarles a gestionarlos positivamente. Ahora bien, el mediador no resuelve el problema, sino que refuerza a que las partes en conflicto lo hagan mediante el fomento de la comunicación y del esclarecimiento de la situación por medio de la escucha activa, las preguntas abiertas y la exploración de emociones y sentimientos.

Los mediadores pueden ayudar a resolver conflictos surgidos entre alumnos, entre alumnos y profesores o entre profesorado y familias; siempre en función de lo que el centro determine en su Proyecto de Mediación o en su Plan de Convivencia. Ahora bien, conviene reseñar que no todos los conflictos son susceptibles de tratarse a través de la mediación. La mediación puede ayudar únicamente en aquellos conflictos en los que no existe un gran desequilibrio entre las partes, no hay excesiva gravedad y existe intención por parte de las partes de solucionar el conflicto dialogando. Sin embargo, no es recomendable mediar un conflicto en el que una de las partes está sufriendo violencia por parte de la otra, puesto que estos tipos de conflictos requieren, al menos en un principio, otro tipo de intervenciones. Tampoco puede aplicarse en aquellos conflictos que ya fueron mediados y las personas implicadas en el mismo no cumplieron lo pactado o en aquellos casos en los que existe una falta de confianza hacia el espacio de mediación.

Por otra parte, cabe decir que la mediación puede solicitarla el alumnado, el profesorado, el personal no docente del centro y las familias del alumnado, es decir, cualquier miembro de la comunidad que haya protagonizado un conflicto y desee utilizar este servicio de manera voluntaria.

Finalmente, nos gustaría destacar que si bien el desarrollo de la mediación en el ámbito escolar ha sido espectacular durante la última década 
(García y López, 2007), todavía queda mucho por hacer: dotar de suficientes recursos humanos y materiales a los centros para que sean estos los que tomen las riendas de todo lo relacionado con la convivencia escolar; elaborar materiales y concretar estrategias pedagógicas que faciliten la mejora de los problemas de deterioro de la convivencia y conductas disruptivas en las aulas; dotar a los propios profesores de una formación pedagógica adecuada que les permita la participación y elaboración de planes de convivencia a modo de ejes vertebrales de los proyectos educativos de centro; propiciar el cambio de mentalidad de todos los sectores de la comunidad educativa en relación con el sistema disciplinario; en definitiva, arbitrar los esfuerzos necesarios para el desarrollo de relaciones sinérgicas entre el campo de la teoría (reflexión intelectual) y la propia práctica (implementación en la realidad).

Solo de esta manera podremos convertir la mediación en un recurso educativo encaminado a la mejora de la convivencia escolar y, a largo plazo, contribuir en la formación de ciudadanos más participativos, responsables y dialogantes, construyendo así un mundo más humano. No podemos olvidar, y permítasenos destacarlo una vez más, que la escuela es un escenario donde los alumnos inician y consolidan sus relaciones interpersonales, a modo de un microcosmos social, y la mediación enseña a participar, a gestionar conflictos, a asumir compromisos, a expresar sentimientos y emociones; en suma: contribuye a que los alumnos reciban una formación integral entroncada en valores y hábitos democráticos.

\subsubsection{Mediación intercultural}

En los últimos años, la necesidad de contar con profesionales específicos que gestionen, pero sobre todo, se especialicen en aspectos organizativos, técnicos y socioeducativos que se relacionen de manera estrecha con la llegada de niños y adultos inmigrantes a las diferentes comunidades autónomas de España ha llevado, entre otras muchas medidas, a la generación de una figura profesional cuyo perfil continúa gestándose día a día: el mediador intercultural. Este profesional, que recibe múltiples denominaciones, como "mediador cultural", "mediador sociocultural", etc., hace posible la mediación intercultural, que puede ser entendida como una apropiación de la cultura desde la premisa inicial de la desigualdad, lo que implica la utilización de recursos, metodologías y procesos sociales y educativos desde la interculturalidad para superar los conflictos de personas etnocul-

Mediaciones Sociales, № 11, II semestre 2012, pp. 47-71. ISSN electrónico: 1989-0494. http://dx.doi.org/10.5209/rev_MESO.2012.v11.41269 
turalmente diferentes a la cultura de acogida y poner en práctica el valor del reconocimiento del otro para, finalmente, caminar hacia la comprensión mutua, solidaridad, participación y la convivencia comunitaria (Martínez, 2007).

En cuanto a su devenir histórico, y partiendo del hecho de que "la intervención de terceros entre partes diferenciadas desde su cultura es algo muy viejo, quizá tan antiguo como los propios contactos culturales y las relaciones interétnicas" (Giménez, 1997, p. 127), se reconoce que, más allá de la necesidad de contar con traductores e intérpretes cada vez que se ponen en contacto diferentes culturas, hecho este que podría remontarse hasta la antigüedad, existen experiencias pioneras en este ámbito de la mediación. En efecto, tal y como señala este autor, en los años setenta comienza a detectarse la actividad de este profesional en Estados Unidos, así como, posteriormente, en Londres, a principios de los años ochenta, dentro de los programas básicos de salud, servicios sociales, alojamiento y educación a los grupos étnicos minoritarios y en los años noventa con el surgimiento de programas NOW (New Opportunities for Women), en el que se capacitó a mujeres belgas, francesas y británicas para ejercer funciones mediadoras.

En lo que respecta al caso español, merecen ser destacadas las iniciativas acometidas desde la Comunidad de Madrid, Andalucía y Cataluña, por su carácter eminentemente precursor. En Madrid nace la Escuela de Mediadores Sociales para la Inmigración-EMSI, en 1995, aunque no sería hasta 1997 en que se produzca la institucionalización del Servicio de Mediación Social Intercultural (SEMSI) (Giménez, 2001). También destaca, en este sentido, otra institución, el CAIM-Centro de Acción Intercultural de Madrid, que forma a los agentes de desarrollo en el actual contexto multicultural. Andalucía, por su parte, se erige como pionera en la divulgación formativa de cursos y seminarios relacionados con la mediación intercultural, de la mano, fundamentalmente, de la ONGD Andalucía Acoge. Finalmente, en Cataluña se detecta un buen número de ONGD y asociaciones, como Desenvolupament Comunitari que, desde principios de los años noventa, han acometido cursos de preparación y capacitación de inmigrantes como mediadores interculturales. La atención de que ha sido objeto esta figura profesional, a través de análisis, investigaciones y estudios, por parte de Llevot (2004 y 2004a), ha supuesto un enclave funda- 
mental para conocer el presente, pasado y futuro del mediador en Cataluña.

Partiendo de la particularidad de que, hoy por hoy, no existe apenas legislación ${ }^{2}$ que avale el quehacer de la mediación intercultural frente a las otras modalidades de mediación, sí que se reconocen, sin embargo, modelos teóricos diferenciados dentro de este ámbito (AEP-Andalucía Acoge, 2002): el modelo institucional surge a partir de la demanda establecida desde las instituciones públicas, prestadoras de servicios sociales, sanitarios y, algo más tarde, educativos; el modelo asociativo, que se difunde desde asociaciones y ONGD; el modelo cooperativo, que se genera desde fórmulas alternativas que tratan de satisfacer las necesidades de mediación intercultural, como son las cooperativas y, finalmente, el modelo autónomo, que se ejerce a nivel particular como profesión liberal.

Centrándonos aquí, en efecto, en el segundo de ellos, por ser el más extendido, el modelo asociativo, cuyos servicios suelen estar externalizados y se prestan por asociaciones que están sujetas a régimen de subvenciones, este se caracteriza por detentar una serie de rasgos iniciales significativos (Martínez y García, 2009): domina el género femenino en esta modalidad de mediación y, una mayoría reveladora, procede de la inmigración, esto es, tienen nacionalidad extranjera. De ahí que defiendan al mediador procedente de otra cultura diferente al de país de acogida, alegando argumentaciones diferenciadas de por qué habría de ser así. Muchas de ellas poseen estudios superiores, realizados en su país. Para concluir este perfil inicial, el buen mediador se identifica, para ellos, con una serie de actitudes personales y relacionales, entre las que este modelo de mediador destaca la empatía, sensibilidad, entusiasmo, espíritu crítico, respeto y tolerancia.

Las funciones del mediador intercultural se reparten de manera general entre el ámbito social y educativo, resumiéndose en labores de acogida, asesoramiento a familias, sensibilización y resolución de conflictos. También detenta funciones específicamente educativas, como son el trabajo de sensibilización en colegios, refuerzos formativos en alumnos inmigrantes y menores y asesoramiento en materia intercultural a colegios y profesores.

2 Si exceptuamos la reciente ley valenciana de Integración (15/2008), en la que aparece la figura y se desarrollan sus funciones.

Mediaciones Sociales, № 11, II semestre 2012, pp. 47-71. ISSN electrónico: 1989-0494. http://dx.doi.org/10.5209/rev_MESO.2012.v11.41269 
En cuanto a su condición laboral, en la actualidad, y en lo que respecta a aspectos organizativos, su situación contractual es relativamente reciente (dos-tres años) y estable, aunque dependiente de proyectos, con todos los obstáculos implícitos y explícitos que ello pueda conllevar. Trabajan en equipos interdisciplinares, con otros profesionales (filólogos, psicólogos, trabajadores sociales, otros mediadores, etc.) y consideran que la programación y planificación de su trabajo es, en buena medida, adecuada, con gran frecuencia en las reuniones.

Existe igualmente una proclividad hacia la idea de la necesidad de consolidar un plan institucionalizado de formación, aunque en este modelo de mediación domina una filosofía de formación más informal, a partir de talleres y cursos breves de formación, alejados de los circuitos de los cursos de postgrado y especialización de la mediación. En cuanto a sus funciones prioritarias, estas se reparten entre el ámbito social y el ámbito educativo: coinciden en funciones de acogida al alumnado inmigrante que va llegando en el transcurso del año, asesoramiento socioeducativo a familias y profesores en materia intercultural y sensibilización y resolución de conflictos culturales, aunque existe una gran diversidad e incluso dispersión de las mismas. Los mediadores de esta modalidad denuncian que existen, en ocasiones, superposiciones en su trabajo con otros profesionales, de lo que cabría deducir que dichas funciones no se hallan todo lo delimitadas que se espera.

Finalmente, se detectan en la figura aspectos virtuosos y, enfrentados a estos, elementos que obligan a precisar mejoras cualitativas en la mediación cultural. Entre los aspectos positivos destacaríamos el hecho de que nos hallamos ante un yacimiento de empleo relativamente nuevo, tanto en su marco teórico, por tanto todavía perfectible, como en su práctica más inmediata: dada su oportunidad, en la actualidad la demanda y la naturaleza de sus impulsores son tan heterogéneos como significativos (ayuntamientos, bancos, ONGD, centros sanitarios, etc.). Frente a estas fortalezas se hallan debilidades inexcusables, hoy por hoy, como la falta de reglamentación profesional a la que ya se ha aludido, así como a la dificultad de gestionar y poner en marcha auténticas redes de mediación (de ahí que se detecte, en efecto, la "soledad del mediador" a la que la figura se ve sometida). En el entorno laboral, los problemas en la planificación, la continua y casi permanente carencia de recursos, la falta de tiempo para la formación 
y para la evaluación, entre otros, llevan incluso a hacer peligrar la no consolidación definitiva de este profesional. Sin embargo, confiamos en que la oportunidad política y transformadora que ofrece esta modalidad de mediación consiga que, lejos de disgregarse, se erija en una de las mediaciones más extendidas y demandadas en nuestras actuales sociedades poliédricas.

A partir de esta descripción, las categorías seleccionadas son:

- Historia, legislación, modelos y rasgos de identidad de mediación de cada ámbito.

- Formación y funciones.

- Aspectos organizativos y laborales.

De cada una de estas categorías, a su vez, se deducen diferentes apartados, que se pueden apreciar en la siguiente fase.

1. Fase sintética: yuxtaposición de tertium comparationis.

A continuación se yuxtaponen los datos ofrecidos desde los dos modelos, a fin de detectar cuáles son los aspectos coincidentes y las señas idiosincrásicas de cada uno de ellos, a partir de los cuatro apartados inferidos en la fase anterior.

1.1. Historia, legislación, modelos y rasgos de identidad de cada ámbito.

La primera Tabla recoge los aspectos fundamentales que sirven de "carta de presentación” a esta figura: orígenes, legislación que la avala, modelos teóricos detectados dentro del mismo para su sistematización, modelo que aquí se va a comparar por considerarlo mayoritario y, finalmente, algunos datos que posibiliten más señas de identidad, a modo de retrato robot de cada uno de ellos. 
«Identidad y responsabilidades socioeducativas del mediador escolar y del mediador...»

Tabla 1. Yuxtaposición de historia, legislación, modelos y rasgos de identidad de mediación escolar e intercultural.

\begin{tabular}{|c|c|c|}
\hline & $\begin{array}{l}\text { MEDIACIÓN } \\
\text { ESCOLAR }\end{array}$ & $\begin{array}{c}\text { MEDIACIÓN } \\
\text { INTERCULTURAL }\end{array}$ \\
\hline $\begin{array}{l}\text { Inicios. Hitos que } \\
\text { fundamentan la } \\
\text { figura. }\end{array}$ & $\begin{array}{l}\text { Estados Unidos (años 70), } \\
\text { Fundación de la National } \\
\text { Association for Mediation in } \\
\text { Education (NAME) (1984). En } \\
\text { España: País Vasco (1993). }\end{array}$ & $\begin{array}{l}\text { Estados Unidos (1974), Londres } \\
\text { (1990), Francia (1992). En España: } \\
\text { Madrid (1995), Andalucía (1990) y } \\
\text { Cataluña: SEMSI, Andalucía Aco- } \\
\text { ge y creación de redes iniciales. }\end{array}$ \\
\hline Legislación vigente. & $\begin{array}{l}\text { No estrictamente de media- } \\
\text { ción. } \\
\text { Referencias: a nivel estatal Ley } \\
27 / 2005 \text {, de } 30 \text { de noviembre, } \\
\text { de fomento de la educación y } \\
\text { la cultura de paz y en la LOE } \\
\text { (2006) de manera implícita; a } \\
\text { nivel autonómico en algunos } \\
\text { decretos reguladores de los } \\
\text { derechos y deberes de los } \\
\text { alumnos y normas de convi- } \\
\text { vencia. }\end{array}$ & $\begin{array}{l}\text { Ley } 15 / 2008 \text {, de } 5 \text { de diciembre, de } \\
\text { la Generalitat, de Integración de } \\
\text { las personas Inmigrantes en la } \\
\text { Comunitat Valenciana. }\end{array}$ \\
\hline $\begin{array}{l}\text { Modelos dentro del } \\
\text { ámbito }\end{array}$ & $\begin{array}{l}\text { - Modelo directivo. } \\
\text { - Modelo transformativo. } \\
\text { - Modelo circular-narrativo. }\end{array}$ & $\begin{array}{l}\text { - Modelo institucional. } \\
\text { - Modelo asociativo. } \\
\text { - Modelo cooperativo. } \\
\text { - Modelo autónomo. }\end{array}$ \\
\hline $\begin{array}{c}\text { Modelo mayoritario } \\
\text { y trabajado aquí }\end{array}$ & Modelo transformativo. & Modelo asociativo. \\
\hline Sexo & Indistinto. & Femenino. \\
\hline Nacionalidad & Indistinta. & Inmigrante. \\
\hline Titulación origen & $\begin{array}{l}\text { Sin titulación } \\
\text { y con titulación. }\end{array}$ & $\begin{array}{l}\text { Sin titulación } \\
\text { y con titulación. }\end{array}$ \\
\hline $\begin{array}{l}\text { Rasgos de carácter } \\
\text { más destacados }\end{array}$ & $\begin{array}{l}\text { Empatía, escucha, confianza } \\
\text { en las personas y en el pro- } \\
\text { ceso de la mediación, pacien- } \\
\text { cia, disponibilidad a la ayuda. }\end{array}$ & $\begin{array}{l}\text { Empatía, sensibilidad, entusiasmo, } \\
\text { espíritu crítico, asertividad, respe- } \\
\text { to, tolerancia. }\end{array}$ \\
\hline
\end{tabular}

Fuente: elaboración propia.

Mediaciones Sociales, № 11, II semestre 2012, pp. 47-71. ISSN electrónico: 1989-0494. http://dx.doi.org/10.5209/rev_MESO.2012.v11.41269 
Como podemos observar, en los dos ámbitos, el origen de la mediación se sitúa en Estados Unidos y siguen caminos paralelos en cuanto a sus orígenes, surgiendo en los años setenta y trasladándose a España en los años noventa.

En cuanto al ámbito legislativo, debemos indicar que en estos últimos años la mediación escolar ha comenzado a plasmarse en algunos documentos legislativos centrados indirectamente en la mediación, seguidos por la mediación intercultural, aunque esta última en un estado mucho más embrionario. Por otra parte, los modelos de fundamentación de ambas figuras difieren de manera evidente.

En relación al género, domina el femenino en la modalidad de mediación intercultural y una mayoría procede de la inmigración, características que son indistintas en el otro modelo. En relación con la titulación, no parece erigirse en rasgo indispensable ni en la mediación escolar (en muchas ocasiones son los propios alumnos los mediadores) ni en la intercultural.

Finalmente, los rasgos de carácter de los mediadores son similares en los dos modelos, constituyendo un requisito indispensable disponer de habilidades necesarias para facilitar una comunicación eficaz (empatía, escucha activa, respeto...).

\subsection{Formación y funciones del mediador}

Tal y como postula Sáez (2009) se hace necesario atender, tanto a la lógica disciplinar como a la lógica profesional, si se quiere lograr una propuesta convergente. Las competencias del mediador de cada uno de los dos modelos, junto con la formación específica en materia de mediación, constituyen dos aspectos cuya importancia estratégica resulta crucial en la consolidación de esta figura: 
«Identidad y responsabilidades socioeducativas del mediador escolar y del mediador...»

Tabla 2. Yuxtaposición de funciones del mediador escolar e intercultural.

\begin{tabular}{|c|c|c|}
\hline & MEDIACIÓN ESCOLAR & $\begin{array}{c}\text { MEDIACIÓN } \\
\text { INTERCULTURAL }\end{array}$ \\
\hline $\begin{array}{c}\text { Formación } \\
\text { específica mediación }\end{array}$ & $\begin{array}{l}\text { Cursos y talleres de media- } \\
\text { ción escolar }\end{array}$ & $\begin{array}{c}\text { Cursos y talleres de mediación } \\
\text { cultural. }\end{array}$ \\
\hline $\begin{array}{c}\text { Especificación } \\
\text { funciones contrato }\end{array}$ & No. & No. \\
\hline Funciones generales & Todas son educativas. & $\begin{array}{l}\text { Repartidas entre el ámbito social } \\
\text { y educativo: acogida, asesora- } \\
\text { miento a familias, sensibilización } \\
\text { y resolución de conflictos. }\end{array}$ \\
\hline $\begin{array}{l}\text { Funciones específica- } \\
\text { mente educativas }\end{array}$ & $\begin{array}{l}\text { Elaborar documentos que } \\
\text { faciliten el proceso de me- } \\
\text { diación, evaluar el funcio- } \\
\text { namiento del servicio de } \\
\text { mediación, proponer mejo- } \\
\text { ras y actuar en los conflictos } \\
\text { surgidos entre miembros de } \\
\text { la comunidad educativa. }\end{array}$ & $\begin{array}{l}\text { Sensibilización en colegios, con- } \\
\text { tactos con menores y adultos } \\
\text { para refuerzo de formación, } \\
\text { asesoramiento intercultural a } \\
\text { profesores (educación intercultu- } \\
\text { ral). }\end{array}$ \\
\hline Funciones prioritarias & $\begin{array}{l}\text { Actuar en los conflictos } \\
\text { surgidos entre los miembros } \\
\text { de la comunidad educativa, } \\
\text { ayudando a que sean las } \\
\text { personas del conflicto las } \\
\text { que lo resuelvan. }\end{array}$ & $\begin{array}{l}\text { Gran dispersión. Depende de } \\
\text { ONGD/asociación contratante. } \\
\text { Normalmente: sensibilización y } \\
\text { resolución de conflictos cultura- } \\
\text { les. }\end{array}$ \\
\hline Tipología de conflictos & $\begin{array}{l}\text { Conflictos escolares surgi- } \\
\text { dos entre alumnos, alum- } \\
\text { nos-profesores, entre profe- } \\
\text { sorado, familia, familia- } \\
\text { profesorado... No son me- } \\
\text { diados conflictos en los que } \\
\text { existe un gran desequilibrio } \\
\text { entre las partes y los que } \\
\text { son excesivamente graves. } \\
\text { Además, debe existir inten- } \\
\text { cionalidad. }\end{array}$ & $\begin{array}{l}\text { Conflictos interculturales de toda } \\
\text { la población. }\end{array}$ \\
\hline $\begin{array}{l}\text { Colectivos preferentes } \\
\text { de acción }\end{array}$ & $\begin{array}{l}\text { Alumnado, profesorado, } \\
\text { personal no docente, fami- } \\
\text { lias... }\end{array}$ & $\begin{array}{l}\text { Población inmigrante: mujeres, } \\
\text { hombres y niños. }\end{array}$ \\
\hline
\end{tabular}

Fuente: elaboración propia.

Por lo que respecta a la "formación específica en mediación", en los dos casos hallamos que se realiza a partir de cursos y talleres directamente relacionados con la temática a abordar.

Mediaciones Sociales, № 11, II semestre 2012, pp. 47-71. ISSN electrónico: 1989-0494. http://dx.doi.org/10.5209/rev_MESO.2012.v11.41269 
Junto a ello, cabe señalar que en ninguna de las dos figuras se suelen especificar las funciones a desempeñar en el contrato laboral contraído, si bien sendas funciones generales se ubican en el ámbito socio-educativo, aunque en estrecha colaboración con otros campos. En el marco específico de las funciones socio-educativas a desarrollar por cada figura, aparecen elementos comunes relativos a la sensibilización y concienciación de todas las partes implicadas, así como al seguimiento para la mejora global.

Por lo que respecta a las funciones prioritarias a desarrollar por cada uno de los mediadores, en el caso del mediador escolar se señalan los conflictos como área prioritaria de intervención; sin embargo, el mediador intercultural muestra una mayor dispersión en función, sobre todo, de la entidad contratante y de los objetivos o necesidades que esta presente.

En cuanto a la tipología de conflictos a que se atiende en cada figura, encontramos una clara diferenciación dado que el mediador escolar se centra en los conflictos que surgen entre diferentes miembros de la comunidad escolar, mientras que el mediador intercultural lo hace en conflictos que implican a toda la población, haciendo especial hincapié en favorecer el cultivo de la interculturalidad. Estrechamente unido a ello, el colectivo al que preferentemente dirige su acción el mediador escolar será el alumnado, profesorado, personal no docente, familias, etc.; por su parte, el mediador intercultural atiende, prioritariamente, a las necesidades y requerimientos de la población inmigrante.

\subsection{Aspectos organizativos y laborales del mediador}

A continuación se analizan las condiciones organizativas y laborales bajo las que se legitima el trabajo del mediador en cada uno de los dos ámbitos: 
Tabla 3. Yuxtaposición de aspectos organizativos y laborales del mediador escolar e intercultural.

\begin{tabular}{|c|c|c|}
\hline & MEDIACIÓN ESCOLAR & $\begin{array}{c}\text { MEDIACIÓN } \\
\text { INTERCULTURAL }\end{array}$ \\
\hline Tiempo contratación & $\begin{array}{l}\text { Cuando los mediadores son } \\
\text { miembros de la comunidad } \\
\text { educativa, estos no son con- } \\
\text { tratados. } \\
\text { Si los mediadores son agen- } \\
\text { tes externos, sí existe contra- } \\
\text { to y aproximadamente llevan } \\
\text { trabajando desde hace cinco } \\
\text { años en algunos centros } \\
\text { escolares. }\end{array}$ & $\begin{array}{l}\text { Aproximadamente desde hace } \\
\text { cinco años. }\end{array}$ \\
\hline Condiciones laborales & $\begin{array}{l}\text { Los alumnos mediadores o } \\
\text { sus familias no tienen contra- } \\
\text { to. } \\
\text { Si los docentes, el psicopeda- } \\
\text { gogo del centro o un educa- } \\
\text { dor social son los mediado- } \\
\text { res, la función de la media- } \\
\text { ción es un complemento a } \\
\text { sus competencias profesiona- } \\
\text { les más amplias. }\end{array}$ & $\begin{array}{l}\text { Contratos en función a proyec- } \\
\text { tos concretos, limitados en el } \\
\text { tiempo. }\end{array}$ \\
\hline $\begin{array}{c}\text { Entidades } \\
\text { contratadoras } \\
\end{array}$ & Administraciones públicas. & $\begin{array}{l}\text { ONGD, ayuntamientos, manco- } \\
\text { munidades de ayuntamientos. }\end{array}$ \\
\hline Trabajo con equipo & Sí. & Sí. \\
\hline Miembros del equipo & $\begin{array}{l}\text { Cualquier miembro de la } \\
\text { comunidad educativa (profe- } \\
\text { sores, alumnos, padres...) y, } \\
\text { en ocasiones, educadores } \\
\text { sociales. }\end{array}$ & $\begin{array}{l}\text { Trabajador social, psicólogo, } \\
\text { otros mediadores (lingüístico...). }\end{array}$ \\
\hline $\begin{array}{c}\text { Detección de } \\
\text { superposiciones en el } \\
\text { trabajo }\end{array}$ & No. & Sí. \\
\hline
\end{tabular}

Fuente: elaboración propia.

El tiempo de contratación es prácticamente el mismo en los dos casos, siendo aproximadamente en 2004 en los otros dos modelos, si bien cabe apostillar aquí que en ambos casos nos referimos a la figura profesional remunerada, dado que a nivel informal existía desde antes. En íntima relación a lo señalado, las condiciones laborales se han desarrollado mucho más en el modelo intercultural, aunque sea siempre perfectible, dado que en los dos modelos, el escolar y el intercultural, las competencias mediado- 
ras se integran y diluyen con el resto de funciones socioeducativas del profesional.

De cualquier modo, en los dos casos, el mediador forma parte de un equipo multidisciplinar al que recurrir en función de las demandas concretas de las diferentes situaciones de mediación, si bien aquí se detecta una diferencia básica entre el mediador escolar y los otros dos: mientras el equipo del primero pertenecerá a la propia comunidad educativa, siendo, por tanto, una función añadida a las responsabilidades propias que como miembro de la institución escolar ya tienen, en el otro se advierte la profesionalización de figuras como el trabajador social, psicólogo e incluso otros tipos de mediadores, como el lingüístico o el comunitario. En íntima relación con este aspecto, resulta altamente llamativo el hecho de que, en este último mediador, el intercultural, se detecten superposiciones en las competencias atribuidas, a diferencia, de nuevo, del escolar.

\section{FASE PROYECTIVA: CONCLUSIONES COMPARADAS}

Como conclusión a los modelos escrutados, así como su interpretación, hemos podido comparar los hallazgos encontrados a fin de dilucidar sus puntos de convergencia, y de defender la competencia educativa que tienen los dos modelos de mediación más relacionados con el ámbito educativo. Desde este marco, la intención del artículo se ha identificado con hallar los aspectos más significativos de cada uno de dichos modelos y analizar por qué los mismos fenómenos se manifiestan de forma diferente en distintos contextos y por qué unas formas de intervención pueden considerarse más apropiadas que otras, a la luz de sus consecuencias sobre los conflictos y, por ende, sobre los protagonistas de la mediación.

De hecho, la "lección más valiosa", utilizando terminología comparatista, que puede extraerse de los modelos, es que podemos contemplar una riqueza de perspectivas de la mediación reclamada desde la heterogeneidad de la diferencia de los escenarios en los que se aplica y sus protagonistas: estudiantes, familia e inmigrantes. Heterogeneidad que, cuando cristaliza de la retórica a la práctica, es decir, de la heurística del modelo a la plasmación práctica de sus acciones, acaba coincidiendo en algunas funciones, pero sin perder de vista el escenario en el que se aplica la mediación.

Mediaciones Sociales, № 11, II semestre 2012, pp. 47-71. ISSN electrónico: 1989-0494. http://dx.doi.org/10.5209/rev_MESO.2012.v11.41269 
Y, como resultado de nuestro trabajo, tras haber aplicado la metodología comparada, podemos concluir corroborando nuestra hipótesis inicial y es que, a pesar de que existen diferencias en la definición de estos dos modelos de mediación, se reconocen aspectos coincidentes que los vinculan a un tronco común: las competencias educativas que adquiere cada uno de ellos. La intervención en la gestión democrática de los conflictos, sea en uno u otro ámbito, constituye la función prioritaria de todo mediador, siendo el proceso y - sobre todo- la participación responsable en el mismo lo verdaderamente idiosincrásico que acredita esta figura. La finalidad básica del mediador no es, por tanto, lograr acuerdos, sino favorecer la comunicación interpersonal, construir espacios de integración compartida y propiciar propuestas de futuro. Para ello, las habilidades que facilitan una comunicación eficaz (empatía, escucha activa, respeto...) se erigen en cualidades indispensables en los dos modelos, sin olvidar el cómo saber trabajar en equipos interdisciplinares. En definitiva, la mediación permite enseñar valores y hábitos democráticos y caminar hacia una cultura promotora de la convivencia, más allá de la mera instrumentalización que supone la solución de los posibles conflictos surgidos en determinadas circunstancias.

Junto a estos aspectos comunes señalados, podríamos añadir, asimismo, que en los dos ámbitos la mediación surge en Estados Unidos y su origen se sitúa en años próximos. Por otro lado y a nivel contractual, constituyen dos figuras profesionales nuevas desprovistas de normativización, lo cual creemos un déficit necesario de subsanar. Sin duda, reivindicamos la profesionalización de las mismas, para lo que se requerirá una tácita clarificación de competencias profesionales, sin olvidar la definición implícita de un marco de referencia común por el que los mediadores puedan guiarse: solo de esta manera, entendemos, se evitarán posibles superposiciones detectadas con otras figuras profesionales. Para tal aspiración, resultará esencial dotar a los mediadores de una formación integral, sistematizada, regulada y de calidad.

Ahora bien, la carencia de recursos humanos, económicos y materiales, la falta de tiempo con el que el profesional cuenta para su evaluación, la todavía desconfianza generalizada hacia la mediación, la escasez de normativas y formación, entre otros, constituyen hoy por hoy algunos obstáculos que dificultan la implantación definitiva de la mediación. Sin embargo, y para concluir, las múltiples iniciativas surgidas en estos últimos años que apuestan por la misma, nos permiten ser optimistas y seguir 
trabajando por su consolidación definitiva, a fin de que la mediación como cultura llegue a los actuales escenarios socioeducativos "para quedarse" tal y como en su momento señalamos (López et al., 2007).

\section{Bibliografía}

AeP Desenvolupament Comunitari-Andalucía Acoge (2002): Mediación intercultural. Una propuesta para la formación. Madrid: Popular.

AgUAdo, $\mathrm{M}^{\mathrm{a}} \mathrm{T}$. et al (2002): "Mediación social en el ámbito socioeducativo. Identificación de necesidades y formulación de propuestas de actuación en contextos educativos". Disponible en http://www.UNED.es/centrointer/mediación

Consultado el 9 de abril de 2009.

Bernal, T. y Andrés, V. (1991): Memoria del Programa de Mediación. Madrid: APSIDE.

CohEn-EMerique, M. (1997): "La negotitation interculturelle, phase essentielle de l'integration des migrants", Hommes \& Migrations, 1208, pp. 9-23.

Diez, F. y TAPIA, G. (1999): Herramientas para trabajar en mediación. Barcelona: Paidós.

ESCUDERO, J. (2009): "Las competencias profesionales y la formación universitaria: posibilidades y riesgos”, Pedagogía Social. Revista Interuniversitaria, 16, pp. 6582.

FERrER, F. (2002): La Educación Comparada actual. Madrid: Ariel.

GALÁN, D. (2008): "Los educadores sociales en los centros de educación secundaria de Extremadura”, Pedagogía Social. Revista interuniversitaria, 15, pp. 57-71.

GARCíA, J.L. (1990): Fundamentos de la Educación Comparada. Madrid: Dykinson.

GARCÍA, L. y LÓPEZ, R. (2007): "Mediación y Sistema Escolar. La convivencia como horizonte”, en R. López, (ed.): $\Upsilon$ llegó para quedarse, las múltiples caras de la mediación. Valencia: Universitat de València, pp. 71-114.

García, L. y Sahuquillo, P.M. (2010): Fundamentos básicos de Pedagogía Social. Valencia: Tirant lo Blanch.

Mediaciones Sociales, № 11, II semestre 2012, pp. 47-71. ISSN electrónico: 1989-0494. http://dx.doi.org/10.5209/rev_MESO.2012.v11.41269 
Gernika Gogoratuz, Centro de Investigación Para la PaZ (1994): Transformación de Conflictos y Mediación como propuesta para el desarrollo de la educación para la paz en el sistema educativo vasco. Informe sobre el programa piloto de transformación de conflictos y mediación entre iguales que se está llevando a cabo durante el curso 1993/94 en el Instituto de Formación Profesional en Barrutialde de Gernika. Gernika: Gogoratuz (GGG).

Giménez, C. (1997): "La naturaleza de la mediación intercultural”, Migraciones, 2, pp. $125-159$.

GIMÉnEZ, C. (2001): "Modelos de mediación y su aplicación en mediación intercultural”, Migraciones, 10, pp. 112-132.

Giménez, C. (2008): “¿Por qué estamos aquí y cómo hemos llegado?”, De Acuerdo. Revista de Divulgación de la Mediación, 3, pp. 5-14.

Hoyos, F. (2007): “Mediación social y comunicación”, en López, R. (ed.): $Y$ llegó para quedarse, las múltiples caras de la mediación. Valencia: Universitat de València, pp. 14-40.

JARES, X. (2001): Educación y conflicto. Guía de educación para la convivencia. Madrid: Editorial Popular.

LÓPEZ, R. y GARCíA, L. (2006): "Convivir en la escuela. Una aproximación reflexiva a sus fundamentos pedagógicos”, Revista Pedagogía y Saberes, 24, pp. 85-97.

Llevot, N. (2004): Els mediadors interculturals a les institucions educatives de Catalunya. Lleida: Pagés Editors.

Llevot, N. (2004a): "La figura del mediador intercultural a les institucions escolars catalanes, perfils real i ideal segons els propis actors”, Papers, 74, pp. 155-173

Malik, B. y Herraz, M. (2005): Mediación intercultural en contextos socioeducativos. Málaga: Aljibe.

Martínez, M.J. (2007): “Compromisos con la vertiente socioeducativa: potencialidades y obstáculos para la profesionalización del mediador cultural”, en López, R. (coord.): $Y$ llegó para quedarse, las múltiples caras de la mediación. Valencia: Universitat de València, pp. 172-214. 
Martínez, M.J. (2008): "Una mirada comparada al contexto internacional: revisión de la realidad del mediador en algunos países. El caso de Italia, Portugal, Suecia y Canadá”, Revista de Educación, 345, pp. 353-376.

Martínez, M.J. (2010): $\Upsilon$ para muestra... Políticas educativas de inmigración y modelos de escuela que practican la interculturalidad. Valencia: Universitat de València.

Martínez, M.J. y LóPEZ, R. (2009): Análisis y práctica de la mediación intercultural desde criterios éticos. Valencia: Tirant Lo Blanch.

MÉNDEZ, E. (1997): La promoción de la mediación familiar en España. Informe grupo de trabajo Centro de Estudios del Menor y de la Familia. Madrid: Ministerio de Trabajo y Asuntos Sociales.

ORTUÑo, P. (2000): "La aprobación judicial de los acuerdos en mediación familiar", Apuntes de Psicología, 2-3, pp. 287-302.

OsMA, M. A. y LOZA, S. (2000): "Mediación familiar: Experiencias y reflexiones desde el ámbito público”, Anuario de Sexología A.E.P.S., 5, pp. 85-99.

Munne, M. y MaC-Cragh, P. (2006): Los diez principios de la cultura de mediación. Barcelona: Graó.

PÉREZ, M.J. (2002): “La mediación escolar, proceso de suma de dos modelos de intervención mediadora en la escuela: los programas de mediación escolar y la mediación social intercultural a su paso por instituciones educativas", Revista Educación y futuro. Disponible en www.cesdonbosco.com/revista/revistas/revista\%20\%ed2ofuturo.html.

Consultado el 15 de enero de 2010.

Ripoll-Millet, A. (2001): Familias, trabajo social y mediación. Barcelona: PaidósTrabajo Social.

Romero, F. (2006): La mediación: una visión plural. Canarias: Gobierno de Canarias.

Rozemblum, S. (1998): Mediación en la escuela. Resolución de conflictos en el ámbito educativo del adolescente. Buenos Aires: Aiqué.

Six, J. F. (1997): Dinámica de la mediación. Barcelona: Paidós.

SLYCK, M. y STERn, M (1996): "La resolución del conflicto en marcos educativos: evaluación del impacto de los programas de mediación prioritarios”, en SUARES,

Mediaciones Sociales, № 11, II semestre 2012, pp. 47-71. ISSN electrónico: 1989-0494. http://dx.doi.org/10.5209/rev_MESO.2012.v11.41269 
M. (coord.): Mediación. Conducción de disputas, comunicación y técnicas. Barcelona: Paidós, pp. 305-323.

SÁEZ, J. (2009): "En enfoque por competencias en la formación de los educadores sociales: una mirada a su caja de herramientas", Pedagogía Social. Revista Interuniversitaria, 16, pp. 9-20.

SuAREs, M. (2003): Mediando en sistemas familiares. Buenos Aires: Paidós.

Torrego, J.C. y Moreno, J. M (2003): Convivencia y disciplina en la escuela: el aprendizaje de la democracia. Madrid: Alianza ensayo.

Uranga, M. (1997): "Experiencias de mediación escolar en Gernika”, Aula de Innovación Educativa, 65, pp. 65-68.

Vinyamata, E. (2003): Aprender mediación. Barcelona: Paidós.

PARA CITAR ESTE TRABAJO EN BIBLIOGRAFÍAS:

MARTÍNEZ USARRALDE, María Jesús, SAHUQUILLO MATEO, Piedad y GARCÍA RAGA, Laura (2012): "Identidad y responsabilidades socioeducativas del mediador escolar y del mediador intercultural: hacia una clarificación de funciones", Mediaciones Sociales. Revista de Ciencias Sociales y de la Comunicación, $\mathrm{n}^{\circ}$ 11, pp. 47-71. DOI: http://dx.doi.org/10.5209/rev_MESO.2012.v11.41269

Mediaciones Sociales, № 11, II semestre 2012, pp. 47-71. ISSN electrónico: 1989-0494. http://dx.doi.org/10.5209/rev_MESO.2012.v11.41269 


\section{Las autoras}

(*) Profesora Titular del departamento de Educación Comparada e Historia de la Educación de la Facultat de Filosofia i Ciències de 1' Educació de la Universitat de València. Sus líneas de investigación están relacionadas con la teoría y la metodología de la Educación comparada, las políticas educativas internacionales, la cooperación al desarrollo y educación y la mediación intercultural desde la perspectiva internacional y socioeducativa. Es codirectora y docente, respectivamente, del módulo sobre Mediación Intercultural del Diploma de Mediación en la Intervención Socioeducativa (novena edición) y del Máster Internacional de Migraciones (sexta edición), ambos de la Universitat de València.

(**) Profesora Contratada Doctora de la Universitat de València. Sus líneas de investigación se relacionan con Mediación y Familia y Menor, principalmente. Es también docente, entre otras, de la materia Pedagogía Social y Familia y Menor en las titulaciones de Pedagogía y Educación Social, respectivamente, así como del módulo "La familia como contexto de desarrollo y educación" en el Diploma de Mediación en la Intervención Socioeducativa y en el Máster Internacional de Migraciones (quinta edición), ambos de la Universitat de València.

(***) Profesora Contratada Doctora y actual Vicedecana de Innovación Educativa y Calidad de la Facultat de Filosofia i Ciències de l' Educació de la Universitat de València. Ha desarrollado, en los últimos años, una trayectoria de investigación en aquellas temáticas relativas a la convivencia y mediación escolar. Es docente, entre otras, de la materia Estrategias de intervención en conflictos organizacionales en el Máster Universitario Política, Gestión y Dirección de Organizaciones Educativas, así como de Procesos y Contextos educativos en el Máster Profesor de Educación Secundaria. Además participa como docente en cursos de convivencia y mediación escolar en diferentes centros educativos de primaria y secundaria.

RECIBIDO: 28 de mayo de 2012 .

ACEPTADO: 17 de diciembre de 2012.

Mediaciones Sociales, № 11, II semestre 2012, pp. 47-71. ISSN electrónico: 1989-0494. http://dx.doi.org/10.5209/rev_MESO.2012.v11.41269 